\title{
Cum Putem Îmbunatati Urmarirea Pacientilor Operati De Hernie Inghinala
}

\section{Moga*}

Secţia Chirurgie, Spitalul Militar de Urgenţă "Dr. Alexandru Augustin" Sibiu, România

“Corresponding author: D Moga, MD, Department of Surgery, Emergency Army Hospital, Dr. Alexandru Augustin" Sibiu, Romania, B-dul Victoriei 44-46, 550024, Sibiu, Romania, Tel: +40 (0) 2692112 09; E-mail: mogadoru@yahoo.com

Received date: 20 December 2013, Accepted date: 30 January 2014, Published date: 9 May 2014

Copyright: (c) 2014 Moga D. This is an open-access article distributed under the terms of the Creative Commons Attribution License, which permits unrestricted use, distribution, and reproduction in any medium, provided the original author and source are credited.

\begin{abstract}
Background: A long-term follow-up of inguinal hernia operated patients is mandatory in order to evaluate the efficiency of the surgical procedures. AIM: The aim of this study is to evaluate a personal follow-up procedure for the operated inguinal hernia patients.
\end{abstract}

Material and Methods: A prospective study including the patients who underwent Lichtenstein tension-free procedure was performed. A prospective follow-up to 1, 6 and 12 months using a Quality of Life (QoL) questionnaire was performed, and the results were carefully analyzed.

Results: 44 consecutive patients operated from June 2011 until May 2012 was included in the study. The median age was 60 years old and men to women ratio were 43 to 44 . To 1 month postoperative check-up, $88.63 \%$ of the patients were presented and at 6 months only $31.81 \%$ from the patients were presented to the postoperative checkup, and after 12 months $58.13 \%$ of the patients answered to QoL questionnaire. In term of QoL, $76 \%$ of the patients had "excellent result" and $24 \%$ "very good result" one year after the procedure. We recorded no recurrence one year after the procedure to the patients who underwent the check-up physical exam. Even the postoperative results are outstanding, the follow-up is only satisfactory from multiple reasons, equally related to doctors, patients and medical system as well.

Conclusions: In our conditions the long term follow-up of the inguinal hernia operated patients is more likely a goal than a routine activity. Further studies and activities (e.g. a National Hernia Registry) will be necessary to improve the patients' follow-up procedure.

Keywords: Groin Hernia; Lichtenstein Procedure; Follow-Up

\section{Introducere}

Intervenţiile chirurgicale efectuate pentru diagnosticul de hernie inghinală sunt printre cele mai frecvente intervenţii practicate în serviciile de chirurgie generală. Anual pe glob sunt efectuate aproximativ 20 de milioane de astfel de operaţii [1]. Numărul lor foarte mare este explicat prin riscul de a face o hernie inghinală de-a lungul vieţii, care este de $27 \%$ în cazul bărbaţilor şi de $3 \%$ în cazul femeilor [2]. Au fost descrise peste 70 de tehnici de cură herniară [3]. Dintre acestea însă, sunt validate în prezent un număr restrâns de intervenții care şi-au demonstrat eficiența: tehnica Lichtenstein, Shouldice, tehnicile laparoscopice.

Eficiența unui procedeu chirurgical este dată de rata complicațiilor postoperatorii (mai ales incidența durerii cronice) și rata recidivei [4,5]. În acest scop urmărirea postoperatorie a pacienţilor este obligatorie.

Scopul studiului de faţă este de a evalua dacă maniera în care se efectuează urmărirea pacienților în serviciul nostru este corectă şi suficientă.

\section{Material şi Metodă}

În Secţia Chirurgie a Spitalului Militar de Urgență Sibiu, în intervalul iunie 2011 - mai 2012, au fost incluși în studiu toţi pacienţii internaţi cu diagnosticul de hernie inghinală, operaţi de către autorul articolului. În perioada mai sus menționată, au fost practicate 44 de operaţii protetice, prin abord anterior, după tehnica Lichtenstein.

Înainte de operaţie, cu ocazia anamnezei şi a semnării consimţământului informat, am încercat să explicăm pe înţelesul pacienţilor ce înseamnă hernia inghinală şi în ce constă intervenţia chirurgicală, cu riscurile şi complicaţiile acesteia. În scopul unei cât mai bune informări a pacienţilor, am elaborat un ghid al pacientului (Ghidul pacientului - Ce este hernia inghinală?), care a fost pus la dispoziţia tuturor pacienţilor care şi-au exprimat disponibilitatea de a1 parcurge.

Pacienţii operaţi, înainte de externare au fost informaţi cu privire la necesitatea controalelor postoperatorii (la 1 lună, la 6 luni şi la 12 luni postoperator), aceste informaţii fiind trecute şi în biletul de ieşire din spital/scrisoarea medicală.

Pentru evaluarea rezultatelor, chestionarele au fost interpretate utilizând următoarea scală: 9-10 puncte (rezultat excelent), 6-8 puncte (rezultat foarte bun), 5-6 puncte (bun), 3-4 puncte (slab), < 3 puncte (foarte slab) [6].

La controlul de 1 an, pe lângă consult pacienţii au fost rugaţi să completeze şi un chestionar (Tabelul 1). Chestionarul a fost trimis prin poştă după 1 an de la operaţie pacienţilor care nu s-au prezentat la control. 
Tabel I: Chestionar de evaluare calitativă şi cantitativă a calităţii vieţii la 1 an după cura herniei inghinale.

\begin{tabular}{|c|c|}
\hline 1) Cum vă simţiţi după cura herniei ? & \\
\hline Mai rău ca înainte & -1 \\
\hline Rău & 0 \\
\hline La fel & 1 \\
\hline Bine & 2 \\
\hline Foarte bine & 3 \\
\hline Excelent & 4 \\
\hline $\begin{array}{l}\text { 2) Aveţi vreuna din suferinţele pe care le-aţi avut înainte de } \\
\text { operaţie? }\end{array}$ & \\
\hline $\mathrm{Da}$ & 0 \\
\hline $\mathrm{Nu}$ & 1 \\
\hline 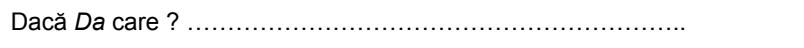 & \\
\hline $\begin{array}{l}\text { 3) Ați dezvoltat vreun simptom sau vreo complicaţie pe care nu aţi } \\
\text { avut-o înainte de operaţie? }\end{array}$ & \\
\hline $\mathrm{Da}$ & 0 \\
\hline $\mathrm{Nu}$ & 1 \\
\hline Dacă $D a$, care dintre ele: & \\
\hline - atrofie testiculară (micşorarea testicolului de partea operată) & \\
\hline - durere cronică & \\
\hline - migrarea plasei & \\
\hline - fistulă cutanată (infecţie cronică) & \\
\hline $\begin{array}{l}\text { Când a apărut ? } \\
\text { specificaţi intervalul de timp scurs de la operaţie în luni: ............. }\end{array}$ & \\
\hline 4) S-a îmbunătăţit activitatea fizică după operaţie? & \\
\hline $\mathrm{Da}$ & 1 \\
\hline $\mathrm{Nu}$ & 0 \\
\hline 5) Sunteţi satisfăcut de operaţie ? & \\
\hline $\mathrm{Da}$ & 1 \\
\hline $\mathrm{Nu}$ & 0 \\
\hline 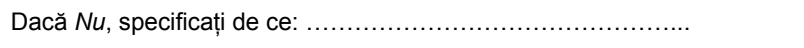 & \\
\hline 6) Aţi recomanda operaţia unui cunoscut? & \\
\hline $\mathrm{Da}$ & 1 \\
\hline $\mathrm{Nu}$ & 0 \\
\hline 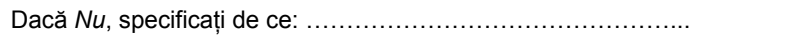 & \\
\hline 7) Hernia inghinală a recidivat? & \\
\hline $\mathrm{Da}$ & 1 \\
\hline $\mathrm{Nu}$ & 0 \\
\hline
\end{tabular}

Dacă $D a$, la ce interval de timp de la operație? .......................

\section{Rezultate}

Au predominat pacienții de sex masculin (43 din cei 44 de pacienți). Vârsta pacienţilor a fost între 19 şi 90 de ani, 33 dintre aceştia (75\%) având peste 50 de ani. Vârsta mediană a pacienţilor a fost de 60 de ani. Pacienţii au provenit din judeţul Sibiu (36 de pacienţi - 81,81\%) şi judeţele limitrofe: Vâlcea (4 pacienţi - 9,09\%), Alba (3 pacienţi 6,81\%), Mureş (1 pacient - 2,27\%). Ca şi mediu de provenienţă 27 dintre pacienţi au fost din mediul urban $(61,36 \%)$ şi 17 din mediul $\operatorname{rural}(38,63 \%)$.

Au fost 38 de cazuri de hernie primară unilaterală, 2 cazuri de hernie primară bilaterală (operate în acelaşi timp operator) şi 4 cazuri de hernie recidivată unilaterală (după procedee tisulare, retrofuniculare).

Pe perioada urmăririi postoperatorii, cu ocazia controalelor am diagnosticat un hidrocel şi 2 hernii inghinale primare, pe partea controlaterală. $\mathrm{Nu}$ a fost diagnosticată nici o recidivă herniară. Unul dintre pacienţi a decedat la 10 luni de la operaţie, fără legătură cu intervenţia chirurgicală.

Prezenţa pacienților la controale a fost următoarea: la 1 lună 39 de pacienţi din $44(88,63 \%)$, la 6 luni 14 pacienţi din $44(31,81 \%)$, iar la 1 an doar 9 pacienţi din 43 (20,93\%). Adăugând la controlul de 1 an şi pacienţii care au răspuns la chestionarul expediat prin poştă (16 chestionare primite), am considerat că am reuşit să urmărim la 1 an 25 dintre pacienţii lotului nostru (58,13\%) (Figure 1).

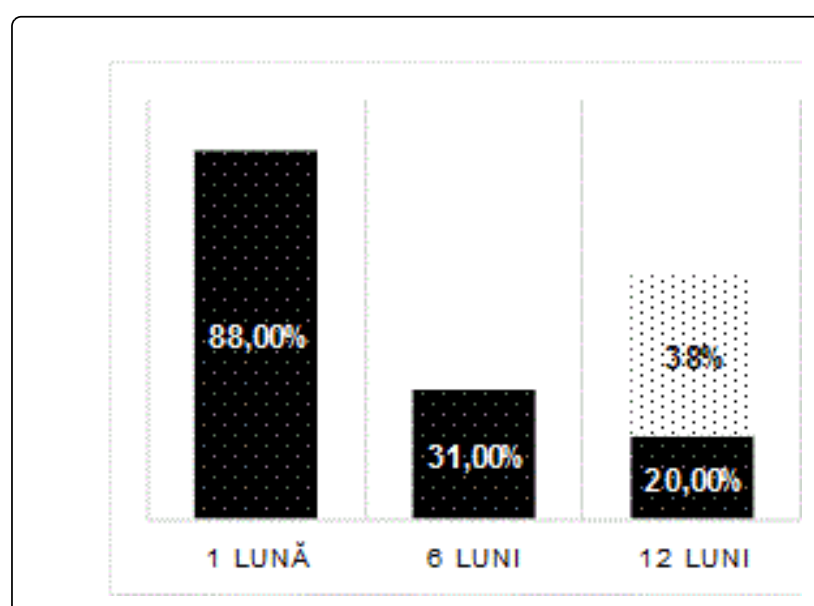

Figure 1: Distribuția pacienților în funcție de prezentarea la control. De notat procentul de $38 \%$ de pacienți care au trimis chestionarele prin poștă.

În urma interpretării chestionarelor, 19 pacienți (76\%) s-au încadrat în categoria rezultat excelent (9-10 puncte) iar restul de 6 (24\%) în categoria rezultat foarte bun (6-8 puncte).

Întrucât numărul de pacienţi prezentaţi la controlul de la 12 luni a fost redus, am analizat la acest interval şi pacienţii care au răspuns prin poştă la chestionar. Complianţa la follow-up din lotul total de pacienţi a crescut odată cu vârsta: $<40$ de ani 2 pacienţi din $9(22,22 \%)$, 
categoria 40-60 ani 5 pacienţi din 11 (45,45\%), > 60 de ani 18 pacienţi $\operatorname{din} 25(72 \%)$.

Ca mediu de provenienţă, au răspuns la controlul de 1 an $61,53 \%$ dintre pacienţii din mediu urban (16 pacienţi din 26) şi 52,94\% dintre pacienţii din mediu rural (9 pacienţi din 17). 63,15\% dintre pacienţii având domiciliul în municipiul Sibiu se regăsesc printre pacienţii controlaţi la 1 an.

\section{Discuţii}

Din multitudinea de tehnici chirurgicale descrise de cură herniară, în prezent s-au selectat un număr redus de procedee ale căror rezultate justifică folosirea lor [2]. Simplificând şi sintetizând şi mai mult lucrurile putem afirma că în prezent, ştiinţific validate şi recomandate pentru aplicare clinică nu au mai rămas decât 3 tehnici: tehnica tisulară Shouldice, tehnica protetică prin abord anterior Lichtenstein şi tehnicile protetice prin abord endoscopic/ laparoscopic (TEP/TAPP) [1].

Pentru a putea vorbi de rezultate competitive în ceea ce privește patologia herniară este necesar un lot mare de pacienţi, cu un procent înalt de pacienţi urmăriţi (85-90\%), pe o perioadă lungă de timp (de preferat 5-10 ani) $[7,8]$.

În România, se pune prea puţin accent pe importanţa urmăririi post-operatorii. În aceste condiții, eforturile individuale de urmărire a loturilor de pacienţi, au şanse mici de reuşită, în condiţiile în care pacientul şi anturajul acestuia nu sunt familiarizaţi $\mathrm{cu}$ importanța controalelor periodice. Acest fapt explică subdiagnosticarea sindromului de durere cronică postherniorafie şi că nu se poate stabili procentul real de recidivă herniară. Deşi sună mai degrabă anecdotic, unii dintre chirurgi cred că, dacă pacientul nu se prezintă la control, înseamnă că e bine".

Nu există procedeu chirurgical herniar infailibil, care să nu aibă recidive. Este însă necesar să practicăm un procedeu, care să aibă un risc cât mai mic de recidivă. Procentul de recidivă este influenţat de tehnica folosită, de experienţa operatorului, metoda şi de durata de timp pe care se face urmărirea [9]. Dacă pentru procedeele consacrate, defectele de tehnică chirurgicală sunt principala cauză de recidivă, folosirea procedeelor istorice reprezintă în sine cauză de recidivă [10].

În lipsa unei urmăriri corecte, cădem cu uşurinţă pradă unor speculaţii prin care credem că şi pacienţii noştri vor avea un risc de recidivă "ideal” (recurenţa herniară este de $<1 \%$ în clinicile specializate în chirurgia parietală) sau eventual putem să credem că nu avem recidive. Aceasta în condiţiile în care se estimează că recidiva după procedeele tisulare istorice atinge $35 \%$ [3].

Cea mai fidelă metodă de urmărire postoperatorie a pacienţilor este prin examinare directă, de către chirurg. Urmărirea trebuie să fie făcută pe termen lung, acest lucru fiind îngreunat de faptul că complianţa pacienţilor scade cu timpul. Dacă pacientul nu se prezintă din proprie iniţiativă la control, care sunt soluţiile? Efectuarea de vizite periodice la domiciliu, metodă folosită de către unele servicii de chirurgie herniară, în condiţiile noastre o considerăm utopică. Alte opţiuni sunt cele legate de expedierea unui chestionar prin poştă (inclusiv poşta electronică) şi respectiv apelul telefonic (răspunderea la întrebările unui chestionar) [11]. Aceste metode sunt utile, dar cu un grad înalt de subiectivitate, putând duce la rezultate incomplete, uneori incorecte, legate de modul în care sunt redactate întrebările şi de nivelul cunoștinţelor medicale al pacienților. Comparând cele 2 metode indirecte de follow-up se consideră că prin apel telefonic procentul de pacienţi urmăriţi este superior celui prin chestionar, întrucât o scrisoare este mai uşor ignorată [12]. Dacă pacientul este contactat telefonic în locul chestionarului este de preferat programarea unei consultaţii. În situaţia pacientului care nu mai locuieşte la adresa cunoscută şi nu poate fi contactat telefonic, s-ar putea încerca obţinerea datelor de contact şi informaţii despre pacient de la medicul de familie [9].

Dificultăţile în urmărirea pacienţilor operaţi pentru hernie inghinală sunt multifactoriale, fiind legate de chirurg, de pacient, de sistemul medical:

\section{Cauze legate de chirurg}

- nu cheamă pacientul la control sau recomandă doar controlul la nevoie;

- nu explică pacientului importanţa controalelor;

- nu acordă timp şi atenție suficientă pacientului prezentat la control, astfel încât pacientul nu mai revine la controalele ulterioare;

- nu ţine evidenţa controalelor;

- operaţia de hernie, cunoscută ca operaţia "rezidentului", frecvent nu este privită cu seriozitatea necesară, astfel încât nici urmărirea nu poate fi privită altfel;

- schimbarea locul de muncă (serviciul chirurgical, oraşul, ţara);

- nu ne informăm colegii că le-am operat recidivele.

\section{Cauze legate de pacient}

- nu a venit la consultația e control programată;

- se simte bine şi nu înţelege utilitatea controlului;

- nu se simte bine şi decide să se adreseze altui chirurg;

- nu se simte bine şi refuză ajutorul medical;

- locuieşte la distanţă de locul în care a fost operat;

- schimbarea localităţii de domiciliu;

- suferă de alte afecţiuni care îl împiedică să respecte programul controalelor;

- decedează.

\section{Legate de system}

- rata recidivelor, procentul de pacienţi urmăriţi nu reprezintă un criteriu de evaluare a calităţii serviciilor medicale;

- pacientul nu este obligat de casa de asigurări să se prezinte la controalele recomandate de către medicul specialist;

- lipsa unui sistem de secretariat pentru efectuarea apelurilor telefonice, expedierea corespondenţei;

- medicul de familie, care cunoaşte din scrisoarea medicală calendarul vizitelor, nu trimite pacientul la control;

- lipsa unui registru naţional de hernii.

În condiţiile în care folosim un procedeu actual pentru patologia herniară şi îl executăm corect, identificarea şi asumarea propriilor recurenţe herniare (într-un procent de $<5 \%$ ) nu denotă lipsa de experienţă, fiind mai degrabă o dovadă de maturitate. Este necesar să ne aliniem recomandărilor ghidului european, pentru a putea oferi pacienţilor noştri servicii medicale de calitate.

Încercând să facem un profil al pacientului pe care ne aşteptăm să putem să-l urmărim postoperator, pe termen mediu şi lung, afirmăm 
că este un pacient de sex masculin, de peste 60 de ani, care locuieşte la oraş (în Sibiu sau în oraşele apropiate).

Privitor la ghidul pacientului, pe un alt lot de 100 de pacienţi, 37 dintre aceştia nu au dorit să-l citească. Explicaţiile au fost multiple, dintre care menţionez "teama de a nu afla prea multe informaţii" sau dimpotrivă, că cunosc în detaliu afecţiunea de care suferă”. Procentul de peste o treime dintre pacienţii care nu-şi doresc să parcurgă materialul de informare al secției spune multe despre nevoia concetăţenilor noştri de a fi informaţi, de a dori să înţeleagă afecţiunea de care suferă, de a avea aşteptări corecte înaintea operaţiei.

Rezultatele obţinute de către noi în prezentul studiu sunt modeste în privinţa procentului de pacienţi urmăriţi la 1 an, astfel încât nu suntem îndreptăţiţi să susţinem că nu avem recidive herniare.

\section{Concluzii}

În condiţiile actuale, urmărirea riguroasă pe termen lung a pacienţilor operaţi de hernie inghinală este o obligativitate, dar rămâne mai degrabă un deziderat decât o activitate de rutină şi un standard în serviciile chirurgicale din România.

- Soluţii pentru îmbunătăţirea rezultatelor şi a urmăririi pacienţilor ar fi:

- informarea mai detaliată a pacienţilor în privinţa afecţiunii, variantelor tehnice de rezolvare chirurgicală, a importanţei urmăririi postoperatorii;

- introducerea în contractul asigurărilor de sănătate a obligativităţi prezentării pacientului la controalele postoperatorii recomandate;

- creşterea disponibilităţii chirurgilor faţă de controalele postoperatorii;

- abandonarea procedeelor istorice neperformante;

- respectarea în detaliu a principiilor tehnicii chirurgicale folosite;

- creşterea procentului de intervenţii protetice;

- promovarea chirurgiei laparoscopice herniare;

- adoptarea Ghidului de tratament al herniei inghinale elaborat de Societatea Europeană de Hernie;

- crearea Registrului Naţional de Hernii.

\section{Acknowledgements}

Mulţumiri asistentei medicale Carla Monoranu, pentru munca benevolă de secretariat efectuată.

\section{Conflict de Interese}

Autorul nu declară nici un conflict de interese.

\section{Bibliografie}

1. Bittner R, Schwarz J. Inguinal hernia repair: current surgical techniques. Langenbecks Arch Surg. 2012; 397: 271-282.

2. Simons M P, Aufenacker T, Bay-Nielsen M, et al. European Hernia Society guidelines on the treatment of inguinal hernia in adult patients. Hernia. 2009; 13: 343-403

3. Amid PK. Groin hernia repair: open techniques. World J Surg. 2005; 29: 1046-1051.

4. Dasari B, Grant Lorraine, Irwin T. Immediate and long-term outcomes of Lichtenstein and Kugel patch operations for inguinal hernia repair Ulster Med J. 2009; 78: 115-118.

5. Messenger DE, Aroori S, Vipond MN. Five-year prospective follow-up of 430 laparoscopic totally extraperitoneal inguinal hernia repairs in 275 patients. Ann R Coll Surg Engl. 2010; 92: 201-205.

6. Oprea $\mathrm{V}$, Matei $\mathrm{O}$, Leucă $\mathrm{D}$, et al. Late results and quality of life after Rives-Stoppa repair for incisional hernias: a prospective clinical study. Chirurgia. 2013; 108: 679-683.

7. Gavrilaş F, Oprea V. Chirurgia peretelui abdominal. Vol. I Hernii primare. Cluj Napoca: Ed. Medicală Universitară „Iuliu Hațieganu”; 2006.

8. Gavrilaş F, Oprea V. Elemente de chirurgie în hernia inghino-femurală. Cluj Napoca: Ed. Oelty; 1998.

9. Staarink M, van Veen RN, Hop WC, Weidema WF. A 10-year follow-up study on endoscopic total extraperitoneal repair of primary and recurrent inguinal hernia. Surg Endosc. 2008; 22: 1803-1806.

10. Gavrilaș F, Oprea V. Chirurgia peretelui abdominal. Vol. II Hernia inghinală recidivată. Hernia incizională. Cluj Napoca: Ed. Medicală Universitară „Iuliu Haţieganu”; 2010.

11. van der Pool AEM, Harlaar JJ, den Hoed PT, Weidema WF, van Veen $\mathrm{RN}$. Long-term follow-up evaluation of chronic pain after endoscopic total extraperitoneal repair of primary and recurrent inguinal hernia. Surg Endosc. 2010; 24: 1707-1711.

12. Visser A, Ubbink D T, Gouma D J, Carel Goslings J. Questionnaire versus telephone follow-up to detect postdischarge complications in surgical patients: randomized clinical trial. World J Surg. 2012; 36: 2576-2583. 